Kendler, K. S., MCGuire, M., Gruenberg, A. M., et al (1993) The Roscommon Family Study. I. Methods, diagnosis of probands and the risk of schizophrenia in relatives. Archives of General Psychiatry, 50, 527-540.

McGuffin, P., OWEn, M. J., O'Donovan, M. C., et al (eds) (1994) Seminars in Psychiatric Genetics. London: Gaskell.

Peter McGuffiN

MiChAEL J. OWEN PHILIP ASHERSON ANNE E. FARMER

University of Wales College of Medicine Cardiff CF4 $4 X N$

\section{Cognitive-behavioural therapy for schizophrenia}

SIR: Patience (BJP, August 1994, 165, 266-267) comments that we overlook two problems in our Editorial (BJP, May 1994, 164, 581-587). He implies that we subscribe to "the notion that simply talking the patient out of delusions is of benefit" far from it, cognitive-behavioural treatment (CBT) of schizophrenia is much broader-based, involving techniques to tackle the range of psychopathology encountered (Kingdon \& Turkington, 1994). Delusions are viewed as neither 'core pathology' nor 'epiphenomena', but beliefs with meaning to the individual which deserve collaborative exploration and understanding.

Patience acknowledges that CBT is effective in depression and useful in other conditions. His statement that "simply using a treatment because it works can only be defended if at the same time efforts are made to understand why it works" is reasonable. Three-quarters of our article explored the phenomenology of psychosis, because we want to understand the nature of the disorder, to guide our interventions. One of us is directly researching psychotic thought processes using the cognitive psychology paradigms that he suggests (John \& Hemsley, 1992; John \& Dodgson, 1994). However, while the aetiology of schizophrenia remains controversial, and the mechanisms of action of interventions with proven efficacy, such as antipsychotic medication, unclear, there can be no justification for abandoning either these or newer interventions which show promise. Even where psychological symptoms are directly caused by organic impairments, for example head injury, patients can be taught cognitive strategies to compensate for functional deficits and reduce distress.

We therefore question Patience's assertion that we should not employ CBT in new areas because we do not yet understand exactly why it works and until the model of Beckian CBT for depression has been updated. This assertion seems to us an excellent example of the sort of faulty assumption, unsupported by evidence, which CBT has proved particularly effective at exposing and, after due collaborative attention to the evidence that is available, amending.

JoHN, C. H. \& DoDGson, G. (1994) Inductive reasoning in delusional thought. Journal of Mental Health, 3, 31-49.

- \& HemsLeY, D. R. (1992) Gestalt perception in schizophrenia. European Archives of Psychiatry and Clinical Neuroscience, 241, 215-221.

KIngdon, D. G. \& Turkington, D. (1994) Cognitive Behavioural Therapy for Schizophrenia. East Sussex: Lawrence Erlbaum.

Carolyn John

Hartlepool General Hospital

Newcastle NHS Trust

DOUGLAS TURKINGTON

\section{Bassetlaw NHS Trust}

DAVID Kingdon

SIR: The current view is still that "with psychotic disorders a cognitive theory of aetiology is not promoted" (BJP, July 1994, 165, 126-130). I believe I owe my full recovery 22 years ago from paranoid schizophrenia to being given a cognitive insight into the aetiology of my condition. At that time I heard voices and thought I was being controlled telepathically. I was told to think of my body as a car with two drivers, myself and the other half of my brain. My trouble was that although I used the other half, I never let it have a go at taking control. In return the other half of my brain made me hear voices and confused me in any way it could.

This therapeutic insight came from a fellow patient in a large mental hospital now closed down. I don't think my psychiatrist knew I had hallucinations - I did not tell him in case he extended my detention period or increased my medication.

Afterwards I gave an account of how cognitive insight had enabled my recovery (Rollin, 1980). I am not the only ex-psychotic sufferer who has used cognitive insight to effect a complete recovery and I know I am not the only one who has been asked to write an account afterwards.

I hope these accounts can be collated, and that it can be shown that giving sufferers from schizophrenia an understandable explanation of their condition does more good than harm.

Rolun, H. R. (1980) Coping with Schizophrenia, pp. 144-147. Andre Deutsch.

West Hall

JeFF THOMAS

Surrey TW9 $4 E E$ 